\title{
As cartas dos Povos indígenas ao Brasil: a construção do arquivo 2000-2015
}

Palavras chave cartas povos indígenas Brasil arquivo

Key-words

letters indigenous peoples

Brazil digital archive

\section{Resumo}

Neste artigo, apresento os caminhos teóricos e metodológicos escolhido para a criação do arquivo digital público das cartas produzidas pelos povos indígenas nos últimos quinze anos e encaminhadas ao Brasil. Além de discutir os modos de seleção dessas correspondências, que hoje circulam nas redes sociais e em portais de notícias dentro e fora do país, analisarei também a construção desse destinatário -o Brasil- e os modos como essas cartas podem ser lidas como manifestos políticos e/ou como escritos biográficos, que ativam questões para uma compreensão dos usos coletivos desse tipo de texto entre os indígenas. Por fim, explicarei como, com a montagem desse arquivo pretendo produzir uma discussão sobre o espaço autobiográfico, que vem sendo produzido por esses povos, para apresentara emergência autoral do sujeito histórico indígena na formação política/literária do Brasil.

\section{Letters from the indigenous peoples to Brazil: the construction of a digital archive 2000-2015}

\footnotetext{
Abstract

This article presents the theoretical and methodological paths chosen for the creation of a digital archive containing letters produced by indigenous people in the last fifteen years and addressed to Brazil. Even today those letters circulate in social networks and in domestic and international websites. Besides discussing the selection of the correspondence, the construction of the addressee -Brazil- will also be analyzed. In order to do so, I will consider the ways those letters can be read: as political manifestos and/ or biographical writings, matters that allow an understanding of the collective uses of this kind of text among the indigenous. The assembly of this archive is intended to produce an esthetic-political panel of the (auto) biographical space that

* Instituto de Letras, Departamento de Letras Vernáculas. Universidade Federal da Bahia. Salvador/ Bahía, Brasil. E-mail: suzanelimacosta@gmail.com
} 
has been composed by the indigenous peoples. Finally, I will explain how this endeavor has been conducted keeping in mind the characterization of the authorial emergency of the historical indigenous subject in the political/ literary education of Brazil.

Pedimos, de uma vez por todas, para decretar nossa dizimação e extinção total, além de enviar vários tratores para cavar um grande buraco para jogar e enterrar os nossos corpos. Esse é nosso pedido aos juízes federais. Decretem a nossa morte coletiva Guarani e Kaiowá de PyelitoKue/Mbarakay e enterremnos aqui (Kaiowá, 2012).

As palavras finais da carta do povo indígena Guarani Kaiowá, das comunidades PyelitoKue/Mbarakay, presentes na epígrafe acima e publicadas pelo CIMI (Conselho Indigenista Missionário), em outubro de 2012, provocaram comoção e impacto nas redes sociais do Brasil. Diante do clamor dos indígenas, um sem número de usuários do facebook manifestaram apoio aos Kaiowá acoplando, em seus rostos/ perfis de identificação, a mensagem Eu sou Guarani-Kaiowá. A carta dos Kaiowá e o ato dos não-indígenas, além de ampla análise por pesquisadores, antropólogos e jornalistas como gesto de solidariedade política e espiritual aos indígenas, provocaram grande repercussão internacional, o que fez com que a situação das disputas de terras indígenas voltasse a ser pauta principal da mídia brasileira no período.

No artigo A Carta Guarani Kaiowá e o direito a uma literatura com terra e das gentes, Marília Librandi (2014) propôs a inclusão da Carta dos Kaiowá no âmbito da literatura contemporânea produzida no Brasil, considerando, entre outras questões, que a posse das terras Guarani Kaiowá "não deveria, pois, estar dissociada do abrigo do terreno literário, sobretudo porque na cosmovisão Guarani, terra e palavra e alma não estão dissociadas" (Librandi, 2014: 168). Junto aos desafios que essa proposta implicaria às historiografias literárias, a autora também defendeu a carta como documento político e cultural e ressaltou como esse tipo de escrita deveria ser componente da história recente do Povo Brasileiro.

Além dos Guarani Kaiowá, outros povos indígenas no Brasil vêm produzindo uma série de narrativas orais e escritas para denunciar os abusos sofridos, a luta pela terra e, principalmente, para continuar a existir como indígenas no território nacional. Assim entre práticas rituais, produção de vídeos, fotografias, material didático e músicas, os povos indígenas também escrevem cartas, produzidas como manifestos políticos e endereçadas ao governo federal e ao mundo, para defender o direito à vida. Cartas sobre suas terras, suas histórias diárias, suas questões políticas e identitárias, cartas sobre suas vidas.

Como a escrita de cartas elaboradas pelos indígenas no Brasil não se inaugura com a carta dos Guarani-Kaiowá, acredito que a sugestão feita por Librandi, para inclusão da carta dos Guarani kaiowá na historiografia literária brasileira, precisa ser ampliada uma vez que há um volume significativo de cartas escritas e produzidas pelos povos indígenas ao longo da história do Brasil -que precisa fazer parte da história e do próprio imaginário do povo brasileiro sobre quem são os indígenas.

Nessas cartas -veiculadas na Internet pelo Instituto Sócio Ambiental (ISA), pela Federação das Organizações Indígenas do Rio Negro (FOIRN), pela 
1. Coordenação das Organizações Indígenas da Amazônia Brasileira (COIAB), pelo Conselho Indígena de Roraima (CIR), Conselho Indígena do Vale do Javari (CIVAJA), Associação dos Povos Indígenas de Tumucumaque (APITU), Articulação dos Povos Indígenas do Brasil (APIB), Articulação dos Povos Indígenas do Nordeste, Minas Gerais e Espírito Santo (APOINME); Articulação dos Povos Indígenas do Pantanal (ARPIPAN); Articulação dos Povos Indígenas do Sudeste (ARPINSUDESTE); Articulação dos Povos Indígenas do Sul (ARPINSUL); Grande Assembléia do Povo Guarani (ATY GUASSU); Coordenação das Organizações Indígenas da Amazônia Brasileira (COIAB).
2. O NEAl iniciou suas atividades em 2010, na Universidade Federal da Bahia, Instituto de Letras, com o objetivo geral de produzir e fazer circular produções artísticas autorais dos povos indígenas, com enfoque nas produções autobiográficas e literárias desses povos.

3. Na etapa da coleta dos dados, o projeto contou coma participação de professores pesquisadores, graduandos e mestrandos. $\mathrm{Na}$ segunda etapa, o pesquisador indígena Carlos Rafael da Silva, Mestre em Ciências Social e analista de política públicas do Ministério da Educação, participou de todo o processo de coleta, seleção, organização e análise das cartas.
Articulação dos Povos Indígenas do Nordeste, Minas Gerais e Espírito Santo (APOINME) e por outras organizações indígenas- ${ }^{1}$ encontramos uma releitura crítica e um conceito histórico/político do Brasil projetados pela voz autoral coletiva/ individual dos indígenas, bem como um outro caminho possível, não mais de representação, mas da auto-apresentação dos indígenas como agentes das suas narrativas. Parte dessas cartas, que circulam fora do âmbito da Internet, encontra-se nas principais organizações nacionais e regionais das populações indígenas e nos acervos da Fundação Nacional do Índio (FUNAI), em suas coordenações regionais espalhadas pelo Brasil.

Interessa-me com a escrita deste artigo apresentar os caminhos teóricos e metodológicos que escolhemos para a criação de um arquivo virtual e gratuito para divulgação dessas cartas. Das 664 cartas que reunimos para a composição deste arquivo, selecionamos 100 cartas produzidas pelos povos indígenas e encaminhadas ao Brasil, no período de 2000 a 2015, para a futura publicação do primeiro livro de cartas autorais indígenas, intitulado As cartas dos Povos Indígenas ao Brasil (2000-2015). Desse modo, além de discutir os modos de seleção dessas correspondências, analisarei aqui a construção desse destinatário -o Brasil- e os modos como essas cartas podem ser lidas como manifestos políticos e/ou como escritos biográficos que ativam questões para uma compreensão dos usos coletivos desse tipo de texto entre os indígenas.

Em 2010 com a criação do Núcleo de Estudos das Produções de Autoria Indígena (NEAI), ${ }^{2}$ elaborei o projeto de pesquisa intitulado Autobiografias indígenas em trinta anos de cartas, com o objetivo central de montar o arquivo das cartas produzidas pelos povos indígenas e encaminhadas por líderes indígenas às organizações internacionais e ao Governo Federal do Brasil, desde a promulgação dos direitos indígenas na constituição de 1988 até a presente data. Como um dos resultados finais desse trabalho, o projeto teve como objetivo publicar e promover a circulação desse material nas escolas públicas de Ensino Básico vinculadas ao NEAI, através da atuação dos professores da rede municipal de ensino, que participam do nosso núcleo de pesquisa.

Com a aprovação do projeto pelo Conselho Nacional de Desenvolvimento Científico e Tecnológico (CNPq) em 2013 iniciamos a pesquisa ${ }^{3}$ com o levantamento das cartas disponibilizadas no espaço virtual, em sites de organizações não-governamentais. Nesta primeira coleta do corpus da pesquisa conseguimos registrar e catalogar 325 publicadas em diferentes sites, datadas entre o período de 2000 até 2010. Em seguida iniciamos a pesquisa dos anos de 2011 a 2015, registrando 339 cartas no catálogo. De um modo geral, as cartas apresentavam situações, contextos e temas fundamentais para uma leitura crítica do Brasil do século XXI, como os significados das comemorações dos 500 anos de Brasil, as macro-políticas públicas de educação, saúde e segurança púbica, a propriedade coletiva e intelectual nas diferentes comunidades indígenas, além das descrições da miséria das populações mais pobres e das temáticas mais constantes: os assassinatos de lideranças e as disputas das Terras Indígenas.

Com o material coletado, decidimos por selecionar para análise as cartas que compreendiam: 1) O marco dos 500 anos do Brasil; 2) $\mathrm{O}$ acesso da população brasileira à Internet (e a conseqüente disponibilização das cartas na Web); 3) A entrada do Partido dos Trabalhadores (PT), na presidência do Brasil. Desse modo, selecionamos respectivamente três mandatos presidenciais para análise das cartas: os anos finais do governo do Presidente Fernando Henrique Cardoso (cartas de 2000 a 2002), os dois mandatos do Presidente Luiz Inácio 
Lula da Silva (cartas de 2003 a 2010) e o primeiro mandato da Presidenta Dilma Rousseff (cartas de 2011 a 2015).

As cartas de 2000 a 2002 foram marcadas pelo momento em que nacionalmente se comemorava os 500 anos do Brasil, contexto no qual diversos grupos indígenas reivindicavam outros significados para a história oficial do país por meio de alguns manifestos, o principal deles foi o chamado Brasil, outros quinhentos. ${ }^{4}$ Nessa disputa, os indígenas apontavam duas principais perspectivas para uma crítica às comemorações dos 500 anos do Brasil: a idéia de descoberta do Brasil -ainda presente no imaginário da maior parte do povo brasileiro- como invasão e a urgência de construir outra relação com a sociedade brasileira para os próximos 500 anos.

Tais perspectivas foram expressas na carta, datada de 22 de abril de 2000, ${ }^{5}$ endereçada aos Presidentes do Brasil e Portugal, Fernando Henrique Cardoso e Jorge Sampaio, ${ }^{6}$ escrita e assinada coletivamente pelo Povo Xavante (Aldeia Eteñiritipá) e pelo Povo Mehinaku (Aldeia Uiaipiuku), que enfaticamente explicavam:

Aos Srs. Presidentes do Brasil e Portugal Fernando Henrique Cardoso e Jorge Sampaio,

Estamos aqui com toda verdade de nossa Tradição. Sem rancor, sem raiva. Mas, também não estamos comemorando nada. Esta não é nossa comemoração. Apesar de toda distância e dificuldade, viemos porque temos que falar com vocês. Estamos aqui para fazer um novo contato. Vivemos neste lugar há muito tempo, muito antes dele se chamar Brasil. Nossos ancestrais andavam aqui em liberdade [...] Hoje vivemos cercados, em pequenos pedaços de terra. Para todo lado que andamos existem sinais daquilo que vocês chamam progresso. Mesmo nossos territórios demarcados continuam sendo ameaçados pelos projetos de desenvolvimento que não levam em consideração nosso pensamento e nossa vida. Não entendemos o significado das palavras democracia e liberdade que vocês tanto usam. Vocês dizem que gostam da terra. Isso não é verdade. Seus descendentes são numerosos mas viraram a face para a verdade da Criação. Mal sabem quem são. O povo brasileiro não conhece o povo indígena [...]. (Xavante Mehinaku, 2000).

As cartas endereçadas ao presidente durante os anos de 2000-2002 cobravam providências em relação às constantes violências sofridas pelos indígenas, devido aos conflitos com a polícia e o exército nas operações dentro de suas aldeias, bem como em relação à devolução de suas terras ancestrais. Essa última questão foi exaustivamente explicitada pelos indígenas, a exemplo da carta de 31 de janeiro de 2002 encaminhada por representantes de diferentes etnias, reunidos para o $2^{\mathrm{o}}$ Fórum Social Mundial, ${ }^{7}$ em Porto Alegre, que, entre muitas palavras de repúdio, diziam:

[...] Como se não bastasse, o presidente FHC continua nos expulsando de nossas próprias terras, como é o exemplo do povo Kaiowá, no Mato Grosso do Sul. E mais grave, está desrespeitando a Constituição Federal em seu art. 231, que garante aos povos indígenas a demarcação das terras que tradicionalmente ocupam, bem como seu usufruto exclusivo. Portanto, discordamos de todas as iniciativas que visem a compra de terras por governos estaduais, desconsiderando as terras tradicionais (Comissão Indígena, 2002). 4. Movimento ocorrido na cidade
de Porto Seguro, Bahia, escolhida como Local-sede da comemoração.

5. Carta entregue ao então Presidente Fernando Henrique Cardoso no dia 23 de abril de 2000. Disponível em: http://brazil.indymedia.org/ content/2004/01/272987.shtml. Acesso em: 16 ago. 2016.

6. Fernando Henrique Cardoso, Presidente do Brasil entre os anos de 1995 a 2003; Jorge Fernando Branco de Sampaio, Presidente de Portugal entre os anos de 1996 a 2006; os dois Presidentes promoveram as comemorações oficias dos 500 anos da "descoberta" do Brasil pelos portugueses.

7. Carta escrita por lideranças indígenas, articulados na Comissão Pós-Conferência, criada durante a Marcha dos 500 Anos no litoral da Bahia. 
Com esse mesmo tom reivindicatório, coletamos onze cartas enviadas durante os anos finais do governo do presidente Fernando Henrique Cardoso (FHC). Como o começo da entrada da maior parcela da população brasileira no mundo da Web tem início no Brasil no meio da década de 2000, há uma menor quantidade de cartas encontradas durante o governo FHC, no período recortado para a pesquisa, uma vez que decidimos fazer coleta somente de cartas que foram publicadas na Internet.

Nos anos de 2000 a 2005, os documentos escritos pelos povos indígenas ainda eram veiculados por meios de comunicação como jornais, jornalistas independentes e organizações não governamentais. Com o maior acesso da população à Internet, o padrão modifica-se. Nos períodos seguintes, as cartas já estão disponíveis em grupos de e-mail, sites indigenistas, blogs e sites mantidos por indígenas ou organizações indígenas. Publicação das cartas na Internet passa a ser um mecanismo de maior difusão das manifestações dos indígenas, se compararmos com o formato impresso. De todo modo, até hoje, as duas formas se mantém entre os indígenas, principalmente na entrega dos documentos produzidos em reuniões com autoridades, seguidas de posterior disponibilização no espaço virtual, ou mesmo na escrita de cartas abertas à sociedade brasileira ou direcionadas aos seus Presidentes.

Por outro lado, com o boom da Internet no Brasil vemos o aumento significativo de cartas escritas pelos indígenas no período do mandado do Presidente Luiz Inácio Lula da Silva e da Presidenta Dilma Rousseff. Desde cartas mais receptivas e esperançosas, nas quais os indígenas, ao saudar e parabenizar os presidentes esquerdistas eleitos, também denunciavam os problemas vividos, até às cartas de repúdio e cobrança de soluções em relação aos problemas vividos em suas terras. É o que ocorre na carta, endereçada ao Presidente Lula, logo na primeira semana do seu primeiro mandato, e publicada em 08 de janeiro de 2003.

Senhor Presidente, Nós, Yanomami, estamos contentes, pois o senhor foi eleito presidente. O senhor prometeu melhorar o Brasil, por isso nós, Yanomami, estamos também nessa expectativa. Ouvimos as palavras de seu discurso e, apesar de não votarmos, demos nosso apoio aqui de longe. Os espíritos de nossos pajés prestaram-lhe apoio, por isso o senhor foi eleito [...] Apesar de não ter nos enviado uma carta, queremos que fique ciente de nosso pensamento e nos apoie. Quando o senhor era candidato lhe enviamos um primeiro documento e não recebemos resposta; esperamos que agora possa nos responder. Senhor Presidente, queremos que proteja realmente nossa terra, que garanta com firmeza nossa demarcação e não deixe que nossa floresta seja destruída. Vocês brancos a chamaram de "Terra da União", portanto, queremos que garantam isso como uma verdade. Não queremos garimpeiros em nossa terra, pois eles a destroem. Por isso, senhor Presidente, tome medidas para impedi-los (Yanomami, 2003).

As cartas encaminhadas ao Presidente Lula e, posteriormente, à Presidenta Dilma, com a participação institucionalizada das lideranças indígenas nos governos locais e nacional, e pela ampliação de certa seguridade social -saúde e educação- em algumas comunidades indígenas, chegaram às centenas. Os programas e espaços de participação, próprios do governo Lula, se tornaram temas recorrentes nas cartas dos indígenas, misturando um tom de descontentamento e reivindicação pela melhoria da qualidade dos serviços oferecidos e, principalmente, pelos pedidos de ações mais efetivas para a política indigenista e a demarcação das terras indígenas. 
Em 2010, com o final da "Era Lula", os Guarani Kaiowá relembram as promessas do Presidente, em um tom muito diferente do que lemos na carta dos Yanomami enviada no começo do primeiro mandato:

Senhor Presidente Lula,

Várias vezes ouvimos o senhor falar e nos prometer pessoalmente que iria resolver o problema da demarcação de nossas terras Kaiowá Guarani. Não entendemos porque isso até hoje não aconteceu. Ouvimos até o senhor pedir isso ao governador. Porém, como ele se manifestou várias vezes contra o reconhecimento de nossas terras, tínhamos a certeza de que ele não só nada faria, como se empenhou em impedir a demarcação. Agora, senhor presidente Lula, o senhor vem aqui na região do nosso território Kaiowá Guarani, em Dourados, sem ter, em quase 8 anos de governo praticamente nada feito pelas nossas terras (Guarani Kaiowá, 2010).

O contexto dessas cartas -e muitas outras endereçadas ao Presidente Lulase repete, quiçá com menos esperança, no governo Dilma. Os grandes empreendimentos para a infraestrutura produtiva do país -como a Usina Hidrelétrica de Belo Monte-, o aumento da produção agropecuária e o conseqüente recrudescimento dos conflitos fundiários, são as temáticas recorrentes nas cartas de 2011-2015, justamente, pelo impacto dessas ações sobre Terras Indígenas. Esse impacto pode ser mensurado tanto pelo aumento das narrativas de assassinatos e criminalização de lideranças indígenas, quanto pelo aumento de normas ou propostas jurídicas no âmbito do Poder Executivo, Legislativo e Judiciário, que propõem a diminuição dos direitos constitucionais indígenas, principalmente sobre a demarcação de suas Terras.

Além dessas temáticas reivindicatórias, nas cartas também encontramos uma diversidade na forma de escrever e narrar o dia-a-dia nas aldeias. Há relatos na forma de documentos finais de encontros entre lideranças indígenas, com maior descrição da legislação, da política indigenista nacional e internacional e com soluções para os problemas relatados; há também cartas mais íntimas, trocadas entre amigos ou entre lideranças e autoridades, com temas sobre a saudade, a alegria dos encontros, as felicitações por conquistas pessoais.

Durante o processo de seleção dessas cartas, fizemos um levantamento da fundamentação teórica necessária para discutir tanto os modos da autoria dos povos indígenas, quanto o que estávamos chamando de arquivo para, primeiramente, compreendermos o que significava catalogar e organizar produções indígenas. Esse exercício exigiu uma ampla releitura da idéia de arquivo e do poder do arquivista de selecionar, incluir/ excluir e de cruzar memória e saberes, isso porque a partir do momento em que há arquivamento, também está em jogo não somente o passado, mas também o futuro (Derrida, 2001).

Ann Laura Stoler (2002) defende que produzir arquivos é também experimentar epistemologias e identificar os mecanismos que criam canonizações e documentação, os modos como certos documentos entram (ou são excluídos) como fatos históricos. Arquivar, dentro da proposta que construímos, diz desse exercício de experimentação e da vontade de apresentar uma versão da história do Brasil, produzida no período de 2000-2015, contada pelas práticas escritas dos povos indígenas. 
Para tanto, foi preciso também não negar o nosso próprio lugar de "seletores" das cartas dos indígenas -lugar também de poder- uma vez que estávamos interessados nas paradoxais dimensões textuais e simbólicas das práticas arquivistas, "como também no seu significado como lugar de encontro- e de violência- entre culturas e saberes; interessados, ainda, nas relações que se estabelecem entre artefatos documentais e arcabouços institucionais, de um lado, e o próprio pesquisador, de outro" (Heymann, 2012: 27).

\section{O Brasil-destinatário}

Quando decidimos registrar as cartas encaminhadas pelos indígenas ao Brasil, eleger o Brasil como destinatário, e como o outro partícipe da vontade reivindicatória e manifesta do indígena, foi nossa primeira prática seletiva, nossa primeira experimentação e o nosso primeiro encontro para uma definição de uma metodologia para organizar as cartas. Mas o que significa, afinal, o Brasil como interlocutor primeiro dos indígenas? Quem é o Brasil-destinatário das cartas escritas pelos índios?

Na primeira seleção das cartas escritas entre os anos 2000 até 2002, recortamos o Brasil-destinatário como o Brasil das comemorações dos 500 anos, que diretamente os indígenas apontavam como o povo ou nação de brasileiros. No segundo momento da nossa análise, o Brasil-destinatário já tinha nome próprio: os dos três últimos presidentes da República e/ou das demais autoridades indicadas por eles para ocupação dos principais cargos públicos no país. Na terceira seleção de cartas, O Brasil não era um destinatário direcionado, mas sim a interlocução, o vocativo, que marcava e convidava os brasileiros para uma conversa particular sobre a situação dos índios hoje.

Nesses três modos de explicar quem é o Brasil-destinatário das cartas dos indígenas há também algo muito comum nas cartas por nós catalogadas: o destinatário ao mesmo tempo em que carregava uma vasta representatividade é também, e principalmente, um ausente. Logo, as cartas dos Povos indígenas também cumprem o destino de ser "um escrito que alguém envia a um ausente para lhe fazer ouvir seus pensamentos." (Grassi, 1998: 2).

Grassi lê essa ausência como um 'espaço entre dois', espaço que a própria lógica da correspondência ativa na relação remetente-destinatário. Logo, a diferença de uma carta para outros escritos pode ser justamente a ordem do encontro e, conseqüentemente, a presença na ausência que a própria escrita assegura. Sendo assim, é também o destinatário que garante a possibilidade dessa interação, fazendo valer tanto a dialogia do que está 'entre dois', quanto os objetivos de quem remete as correspondências.

Daí o fato de entender o Brasil-destinatário tanto como representante autorizado a responder às reivindicações dos indígenas, quanto como o espaço simbólico que conclama o leitor qualquer, os brasileiros sensíveis e partícipes da causa indígena. Com essa definição construímos o desenho geral do arquivo, catalogando e analisando em notas de rodapé as correspondências destinadas aos Presidentes da República, o que também fizemos com as cartas que não possuíam destinatário nominal, mas que evocavam o povo brasileiro como seu interlocutor direto. Assim no Brasil-destinatário dos índios e nos modos de construir essa interlocução, o que se evidencia é que o destino dessas cartas terá sempre no coletivo a sua razão dialógica. 
Todavia, as cartas dos indígenas não dizem somente de um 'espaço entre dois', como definiu Grassi, uma vez que essa idéia de correspondência não se cumpre aos modos do que o gênero exige. Isso porque, além de cartas que embaralham as relações públicas e privadas, estamos diante de cartas-manifestos, cartasdenúncias, cartas-documentais, tornadas públicas pelos próprios remetentes. Dessa forma, as cartas dos indígenas não são somente um gênero específico de escrita, mas uma diversidade de textualidades que têm mais na vontade dialógica, do que na própria realização dessa interlocução, a singularidade do tipo de escrita que comumente chamamos de carta.

Relembrando Foucault (2004) e o seu texto "A escrita de si", o que está em jogo quando se escreve cartas são os modos de dizer do 'eu/outro' no caminho do próprio cuidado. Assim, o dialogismo na escrita de uma carta se traduz no descentramento que o remetente constrói quando escreve sobre 'si' (Costa, 2013), mesmo que a resposta do destinatário tenha se perdido no tempo, tenha sido extraviada ou, simplesmente, não exista.

No sentido proposto por Arfuch (2010), essas diferentes textualidades dizem da formação de um espaço biográfico que considera o tipo de interlocução, sua situação e as diversas esferas e funções da comunicação em jogo. Daí o fato de apostarmos que nas cartas dos diferentes povos indígenas, o efeito-sujeito do ato biográfico diga muito mais do problema de encontrar um lugar de sujeito do que o lugar do sujeito (Arfuch, 2010). Para Arfuch, a diferença desse paradoxo refere-se ao questionamento do próprio pertencimento da identidade narrativa, que também é um "problema de inscrição da temporalidade no espaço autobiográfico", ora movido pelas perguntas: "quem fala na instância atual do relato? Quem é o sujeito da história?" (Arfuch, 2010: 115)

Assim, quando decidimos por construir o arquivo das cartas consideramos dialogicamente as remissões entre o espaço e o gênero, para colocarmos também em discussão a questão da subjetividade indígena na formação política/literária do Brasil: seus nomes próprios, seus rostos e sua identidade individual/coletiva. Pensando nisso, fizemos uma seção de cartas individuais, assinadas e registradas com os nomes dos indígenas e construídas na simultaneidade da montagem do nós-povo e do eu-singular, ainda que o teor dessas correspondências e o tom repudiador e denunciante sejam bem parecidos com os das demais cartas enviadas aos Presidentes.

Do imaginário popular ao âmbito acadêmico/político, as idéias sobre os índios no Brasil excluem a primeira pessoa do singular para representar os grupos étnicos pelas suas assinaturas coletivas. Quiçá por isso, falar em cartas escritas, ou em quaisquer outras escrituras do campo das biografias ou autobiografias pelos índios, é um tema quase inédito na etnologia indígena brasileira. Por outro lado, tanto o protagonismo indígena nos movimentos políticos liderados por caciques e demais lideranças, quanto as escritos dos professores e estudantes indígenas em suas atividades nas escolas e Licenciaturas, nos apresentam, há mais de décadas, os modos de auto-legitimação da primeira pessoa do singular nos seus discursos, porém configurados sob a rubrica do nome coletivo do grupo étnico ao qual pertence. O que, paradoxalmente, também nos leva a pensar que os escritos indígenas não são nem propriamente individuais, nem em si coletivos.

Ainda que as práticas escritas, individuais ou coletivas, já tenham se tornado uma atividade comum entre os indígenas, há poucos estudos ou referências para pensarmos em produções autobiográficas de autoria indígena, como as 
cartas, e a formação dos seus pressupostos a partir das representações do 'eu' indígena. No entanto, há uma série de questões e tensões que envolvem esse modo de escrever, não só porque nele entendemos as relações saber/poder negociadas e construídas dentro e fora da comunidade, mas também porque na assinatura autoral individual está presente, além do nome indígena, o seu próprio rosto.

Na sugestão da pesquisadora Marília Librandi (2014) para que a carta dos Kaiowá seja parte da Literatura brasileira também está expressa a idéia de que precisamos atentar aos diferentes usos de linguagens e suportes de escrita produzidos pelos indígenas para se autorizarem como produtores dos seus próprios discursos. O paradoxo dessa questão é que no imaginário corrente no Brasil sobre o indígena, ter um rosto é o mesmo que deixar de ser índio; em outras palavras, é o mesmo que dizer: quando o índio se 'apropria' das lógicas tecnológicas dos não-índios eles deixam de ser indígenas.

Não é à toa que uma das diferenças da carta dos Guarani-Kaiowá para as outras cartas/manifestos produzidas por indígenas é que a sua mensagem final acaba ratificando a representação mais comum ao imaginário coletivo, quando se fala da condição de sujeito histórico dos indígenas no Brasil: sua identidade de quase-morte ou de morte em si. Nesse sentido, os perfis ‘ Eu sou Guarani-kaiowá' de outra maneira também diziam que diante da sua morte, e por causa dela, nós somos vocês; diante da sua morte, quiçá só por causa dela, nós reconhecemos quem vocês são, nos reconhecemos em você.

Quando se afasta o imaginário do morto ou do anúncio da sua morte, há sobre o indígena no Brasil uma cobrança de permanência fixa em um passado que ninguém sabe ao certo nomear muito bem. Se estar vivo e se é índio no Brasil, seja através de laudos antropológicos, seja através dos direitos constitucionais, precisa quase sempre de condicionantes externos que lhe afiram a identidade, caso contrário, estará novamente morto. Para esse corpo os discursos das identidades descentradas, híbridas, performatizadas ou nômades de nada valem. Paira sobre a identidade indígena dúvida, cobrança, desconfiança e, principalmente, a necessidade de provas para a sua legitimidade, seu reconhecimento.

Ausentes como sujeito-autor da sua própria história, também ausentes como intelectuais, artistas e líderes políticos nas historiografias oficiais; sem nome próprio, quando presentes nos discursos midiáticos, ser índio no Brasil impõe à noção de identidade dois lugares ambíguos e suplementares entre si: a presença em nome da morte ou a existência por meio das faltas.

Também não é à toa que diante do volume de cartas escritas pelos povos indígenas não haja repercussões, pesquisas, respostas, interação ou qualquer tipo de relação com e sobre esses documentos. São muitas as pesquisas -e de incontestável relevância- que analisam as cartas produzidas sobre os indígenas para uma reflexão crítica da história e da literatura do Brasil, porém, há uma lacuna significativa na abordagem dessa mesma reflexão quando esses escritos são da autoria dos próprios indígenas.

Assim, a construção deste arquivo e sua futura publicação em formato de livro -além da sua inegável relevância política- também fomentarão pesquisas que trarão à tona um problema pouco referenciado no campo dos estudos da crítica histórica e biográfica: os escritos autobiográficos e/ou auto-etnográficos e a própria autoria dos indígenas em documentos que registram sua versão 
da nossa história. A publicação dessas cartas contribuirá para fazer circular um material inédito, que colocará em veiculação, principalmente nas escolas e universidades brasileiras, outra versão do Brasil Contemporâneo: uma versão recontextualizada, narrada e criada pelo corpo autoral e vivo dos Povos indígenas.

\section{Agradecimentos}

Ao Conselho Nacional de Desenvolvimento Científico e Tecnológico (CNPQ) pelo apoio financeiro à pesquisa.

Aos Povos indígenas que cederam suas correspondências para a construção do arquivo.

Ao pesquisador indígena Carlos Rafael da Silva (Rafael Xucuru-Kariri), pela parceria durante a coleta dos dados para a pesquisa. 


\section{Q Referências}

» Arfuch, L. (2010). O espaço biográfico: dilemas da subjetividade contemporânea. Trad. Paloma Vidal. Rio de Janeiro, EdUERJ.

" Comissão Indígena (2002). Carta Il Fórum Social Mundial. Disponível em internet: http:// memoriafsm.org/. Acesso em 21 de outubro de 2016.

" Costa, S. L. (2013). O que (ainda) podem as cartas? Interdisciplinar VIII (19): 87-98.

»Cunha, M. C. da (2012). Índios no Brasil: história, direitos e cidadania. São Paulo, Claro Enigma.

"Derrida, J. (2001). Mal de arquivo: uma impressão freudiana. Trad. Claudia de Morais Rego. Rio de Janeiro, Relume Dumará.

" Foucault, M. (2004). Ética, sexualidade e política. São Paulo, Forense Universitária. (Coleção Ditos e Escritos V).

» Grassi, M. (1998). Lirelépistolaire. Paris, Dunod.

" Kaiowá, G. (2010). Carta Kaiowá Guarani ao Presidente Lula. Disponível em internet: https://www.ecodebate.com.br/2010/o8/27/carta-kaiowa-guarani-ao-presidente-lula/. Acesso em 22 de agosto de 2016.

» Kaiowá, G. (2012). Carta Guarani Kaiowá de PyelitoKue/Mbarakay. Conselho Indigenista Missionário (website). Brasília: CNBB, 8 out. Disponível em Internet: http://goo.gl/ GWZy2l. Acesso em 20 de outubro de 2012.

" Krupat, A. (1989). For Those Who Come After: A Study of Native American Autobiography, University of California Press.

» Heymann, L. Q. (2012). O lugar do arquivo: a construção do legado de Darcy Ribeiro. Rio de Janeiro, Contra Capa/ FAPERJ.

»Librandi, M. (2014). A Carta Guarani Kaiowá e o direito a uma literatura com terra e das gentes. Estudos de literatura brasileira contemporânea 44: 165-191.

"Stoler, A. L. (2002). Colonial arquives and thearts of governance, Archival Science 2, Dordrecht: 87-109.

» Xavante, P. \& P. Mehinaku (2000). Carta comemoração 500 anos. Disponível em Internet: http://brazil.indymedia.org/content/2004/01/272987.shtml. Acesso em 16 de agosto de 2016.

» Yanomani, P. (2003). Carta enviada ao Presidente Luiz Inácio Lula da Silva. Disponível em Internet: http://www.proyanomami.org.br/vo904/index.asp?pag=noticia\&id=1442. Acesso em 22 de agosto de 2016. 